DOI 10.37882/2223-2982.2020.06-2.19

\title{
ФУНКЦИОНИРОВАНИЕ ПРЕДИКАТИВНЫХ ПРАГМАТИЧЕСКИХ МАРКЕРОВ В ДИАЛОГЕ ПЕРСОНАЖЕЙ Ч. ДИККЕНСА
}

\section{PREDICATIVE PRAGMATIC MARKERS FUNCTIONING IN THE DIALOGUE OF CH. DICKENS CHARACTERS}

N. Merkuryeva

Summary: The work deals with dialogic unities composed with sentences including predicative structures called pragmatic markers; phrases like I think, I hope, I believe, I am sure are under analysis. The lexical and grammatical variety of the markers are shown, and their placing in retorts sentences for beginning, developing and finishing a conversation, and functioning as the means of creating emotional speech, filling different kinds of pauses, showing speech habits of the characters are investigated. The linguistic material is taken from the dialogues of $\mathrm{Ch}$. Dickens novel "Christmas Carol". Some conclusions about the diversity of predicative pragmatic markers which were widespread in the middle of XIX century are made, and the using of the markers, as English dominant communicative features manifestation, by different social classes representatives is discussed.

Keywords: words and phrases: pragmatic markers, historical syntax, spoken interaction, authorial styles.
$\mathrm{B}$ ключение в предложения модально-предикативных структур / think, I suppose, I hope, I hear и пр. - широко распространенное явление современной диалогической речи. Поэтому разнообразие таких структур и их функционирование в устной и письменной речи привлекало и продолжает привлекать внимание исследователей. Говоря о подобных структурах, пользуются терминами «позиционные маркеры» [11], «прагматические маркеры» [4], «дискурсивные маркеры» [9, 11]. Имеются данные по разнообразию маркеров, функционирующих на современном этапе в разных стилях речи $[6,7$, $9,15]$. Исследованию подобных структур, находившихся в употреблении в другие исторические периоды, уделяется гораздо меньшее внимание.

Как известно, изучение исторического функционирования языковых явлений имеет свою специфику, главным образом связанную с характером анализируемого материала, отсутствием источников «живой» речи. С целью получить представление об употребляемых в середине XIX в предикативных прагматических маркерах, мы изучили их разнообразие в репликах диалогов персонажей произведения Ч. Диккенса, основываясь на предположении, что текст известного писателя-классика Викторианского периода, изданный в 1843 г., благо-
Меркурьева Наталья Юрьевна

старший преподаватель, Московский городской университет управления Правительства Москвы nata2lya1@mail.ru

Аннотация: В работе рассматриваются диалогические единства, реплики которых включают предложения с прагматическими маркерами, модальнопредикативными сочетаниями / think, I hope, I believe, I am sure и др. Материал для исследования подобран из диалогов повести Ч. Диккенса «Рождественская песнь в прозе». Показано употребление маркеров в предложениях речи персонажей для зачина, развития и завершения диалога, функционирование маркеров в качестве средства придания эмотивных оттенков речи, заполнения разных видов пауз, указания на речевые привычки действующих лиц. Сделаны заключения о разнообразии предикативных прагматических маркеров, находившихся в употреблении в 40-х годах XIX в., обсуждается их использование представителями разных социальных слоев в качестве проявления доминантных черт английского коммуникативного поведения.

Ключевые слова: диалогическая речь, диалогическое единство, прагматические маркеры, дискурсивные маркеры, авторский стиль.

даря богатству языковых форм, разнообразию деталей описания бытовых сцен, точности и красочности передачи особенностей речи современников, может служить источником языкового материала для исследования структур, находившихся в речевом обиходе во время написания произведения.

Материалом для анализа послужили диалогические единства (ДЕ), созданные Ч. Диккенсом при написании диалогов в повести «Рождественская песнь в прозе» (после иллюстрирующих примеров на английском языке будут указаны страницы из источника [13], при цитировании текста перевода, выполненного Т. Озерской, - страницы из источника [3]). В качестве объектов изучения были выбраны реплики, содержащие предложения с модально-предикативными сочетаниями, прагматическими маркерами I know, I say, I believe, I assure you и пр. Изучалось лексико-грамматическое разнообразие маркеров, их положение и функции в предложениях, составляющих ДЕ, способы представления реплик с изучаемыми предложениями. Результаты исследования следующие.

При создании ДЕ Ч. Диккенс использует рассматриваемые структуры в качестве компонентов в предложе- 
ниях реплик-зачинов, реплик-реакций, обеих реплик ДЕ.

В ДЕ (1) предложение с I hоре размещается непосредственно после приветствия и входит в состав репликизачина:

(1) "My dear sir," said Scrooge, quickening his pace, and taking the old gentleman by both his hands, "how do you do? I hope you succeeded yesterday. It was very kind of you. A merry Christmas to you, sir!"

"Mr Scrooge?" (p. 119)

"Приветствую вас, дорогой сэр, - сказал Скрудж, убыстряя шаг и протягивая обе руки старому джентльмену. - Надеюсь, вы успешно завершили вчера ваше предприятие? Вы затеяли очень доброе дело. Поздравляю вас с праздником, сэр!" "Мистер Скрудж?" (с. 113)

Инициирующую реплику персонажа Ч. Диккенс делает весьма объемной, используя при ее формировании обращение, клишированные сочетания приветствия и поздравления, среди которых размещается интересующее нас предложение I hope you succeeded yesterday., выражающее осторожный намек на недавние события, и на то, что эти события небезразличны говорящему. Это предложение, в совокупности с последующим It was very kind of уои., демонстрирующим одобрение, осуществляет подготовку собеседника к тому, что будут обсуждаться известные обоим детали. Обращаясь к человеку, которого недавно обидел, Скрудж быстро говорит предложение за предложением, не давая собеседнику «вставить слово». Отзывная реплика "Mr Scrooge?" указывает на то, что Скрудж выбрал правильную тактику - старый джентльмен выражает крайнее удивление и растерянность, не может подобрать слов, хотя бы для того, чтобы проявить вежливость, однако он вынужден остановиться и начать разговор.

В ДЕ (2) маркер / think используется в реплике-реакции:

(2) "I am very sorry, sir," said Bob. "I am behind my time."

"You are!" repeated Scrooge. "Yes, I think you are. Step this way, sir, if you please." (p. 120)

"Прошу прощения, сэр", - сказал Боб. - "Я в самом деле немного опоздал." "Ах, вот как! Вы опоздали?" - подхватил Скрудж. - "О да, мне тоже сдается, что вы опоздали. Будьте любезны, потрудитесь подойти сюда, сэр." (с. 116)

Стараясь сделать акцент на том, что клерк пришел с опозданием, Скрудж отвечает на извинение, используя эллиптическую структуру Үou are, затем повторяет ее еще раз, при этом высказывание получает большую весомость, предваряемое восклицанием Yes и структурой I think. Многозначительная пауза, между Yes и уou are здесь была бы очень уместна. Можно предположить, что маркер выполняет роль заполнителя такой паузы.

В следующем примере прагматические маркеры упо- требляются автором при создании предложений обеих реплик, зачинающей и реагирующей:

(3) "We're not going to pick holes in each other's coats, I suppose?"

"No, indeed!" said Mrs Dilber and the man together. "We should hope not." (p. 107)

"... Ворон ворону глаз не выклюет." "Да уж верно, нет!" сказали в один голос миссис Дилбер и мужчина. "Уж это maк." (с. 95)

В достаточно щекотливой ситуации, когда речь идет о купле-продаже украденного у покойного имущества, маркеры употребляются и продавцами и покупателем. Старьевщик, вполне возможно, уже привыкнув к подобным случаям, приободряет своих клиентов, добавляя к известной пословице маркер / suppose и, как показывает вопросительный знак, скорее всего, произносит реплику с повышением тона, демонстрируя одобрение и дружелюбие. Люди, принесшие вещи на продажу, сильно смущены, что совершенно четко показано их многословным ответом No, indeed! We should hope not., все компоненты которого могут быть заменены одним словом-предложением No.

Маркеры употребляются в предложениях, которые обеспечивают зачинание, пролонгирование, завершение диалога, что иллюстрируется далее примерами (4)-(6).

Два почтенных джентльмена, сняв шляпы, заходят в контору Скруджа и, поклонившись ему, начинают беседу. Для этого автор строит ДЕ (4):

(4) "Scrooge and Marley's, I believe," said one of the gentlemen, referring to his list." (...)

"Mr Marley has been dead these seven years," Scrooge replied. (p. 60)

"Скрудж и Марли, если не ошибаюсь?" спросил один из них, сверившись с каким-то списком. (...) "Мистер Марли уже семь лет как покоится на кладбище," - отвечал Скрудж. (с. 14)

Маркер / believe сопровождает эллиптическое предложение, полная структура которого могла бы быть, например, такой: Is it Scrooge and Marley's counting-house?. Несколько большую степень уверенности, чем этот общий вопрос с инверсией, выразил бы декларативный вопрос It is Scrooge and Marley's counting-house?. На случай непредвиденной ошибки, вероятность которой невысока, но все же имеется, к редуцированной структуре Scrooge and Marley's, которую автор предпочитает полной, добавлен маркер.

В отрывке (5) сочетание I think также комбинируется с эллиптической вопросительной структурой, представленной одним словом Something:

(5) "What is the matter?" asked the Ghost.

"Nothing particular," said Scrooge. 
"Something, I think?" the Ghost insisted.

"No," said Scrooge... (p. 81)

Тут Скрудж почувствовал на себе взгляд духа и запнулся. "Что же ты умолк?" - спросил его дух. "Так, ничего," - отвечал Скрудж. "Ну а все-таки?" - настачвал дух. "Пустое," - сказал Скрудж (...) (с. 49)

Скрудж, очевидно, не намеревается отвечать на неприятный для него вопрос What is the matter? и пытается уйти от ответа, говоря Nothing particular. Настойчивость собеседника показана репликой Something, I think?, которую дополнительно сопровождают слова автора the Ghost insisted. Такая реплика не может быть проигнорирована и Скруджу приходится давать ответ.

Употребление маркера в предложении реплики, завершающей ДЕ, показано в примере (6):

(6) "I saw an old friend of yours this afternoon."

"Who was it?" (...)

"Mr Scrooge it was. (...) His partner lies upon the point of death, I hear; and there he sat alone. Quite alone in the world, I do believe." (р. 84)

"А я видел сегодня твоего старинного приятеля." "Кого же это? (...) Мистера Скруджа?" "Вот именно. (...) Его компаньон, говорят, при смерти, и он, понимаешь, сидит там у себя один-одинешенек. Один как перст на всем белом свете." (с. 55)

Оба предложения реплики, завершающей ДЕ, строятся автором в сопровождении прагматических маркеров I hear и I do believe. Первый указывает на то, что передаваемая информация была получена от третьих лиц, а второй - на то, что говорящий сам пришел к высказываемому заключению. Использование I do believe вместо / believe, вероятно, продиктовано желанием показать высокую степень уверенности в том, что дела обстоят именно так.

Говоря о функциях обсуждаемых прагматических маркеров, полностью согласимся с исследователями $[1,4,7,14]$ и многими другими, указывающими на полифункциональность подобных структур.

Употребление прагматического маркера в качестве средства заполнения паузы, когда говорящий пытается выиграть время, подбирая слова, скрывает неуверенность или растерянность, иллюстрирует ДЕ (7):

(7) "Is that the chance and hope you mentioned, Jacob?" he demanded in a faltering voice.

"It is."

"I - I think l'd rather not," said Scrooge. (p. 70)

"Уж не об этом ли ты похлопотал, Джейкоб, не в этом ли моя надежда?" - спросил он упавшим голосом. "В этом." "Тогда... тогда, может, лучше не надо?" сказал Скрудж. (с. 30)
На замешательство Скруджа, поставленного перед фактом, что его будут посещать привидения, указывает пауза, маркированная пунктуационным знаком, тире, а постановка I think сразу же после тире позволяет нам с высокой степенью уверенности говорить о функционировании маркера для заполнения этой паузы.

Способствовать продвижению разговора «на шаг вперед» - еще одна весьма характерная функция для обсуждаемых маркеров. Так, например, инициирующая реплика в ДЕ (8), построенная без маркера, She died a woman and had children, означала бы лишь констатацию того, что данный факт говорящему известен и не способствовала бы формированию дальнейшего диалога. Добавление маркера as I think придает реплике некую незавершенность и побуждает слушающего к формированию ответной реплики.

(8) "She died a woman," said the Ghost, "and had, as I think, children."

"One child," Scrooge returned. (p. 78)

"Она умерла уже замужней женщиной," - сказал дух. "И, помнится, после нее остались дети." "Один сын," - поправил Скрудж. (с. 44)

Маркер / think в отзывной реплике ДЕ (9) используется для смягчения категоричности при возражении, когда речь заходит о качестве обеда:

(9) "... He don't lose much of a dinner."

"Indeed, I think he loses a very good dinner," interrupted Scrooge's niece. (p. 98)

"...Лишился обеда, хотя и не бог весть какого." "А я полагаю, что вовсе не плохого," - возразила племянница (...) (c. 80)

Среди особенностей английского коммуникативного поведения известны некатегоричность, антиконфликтная ориентация общения, смягчение резкости высказывания, нелюбовь к спорам, невмешательство в чужие дела, соблюдение privacy [2, с. 41; 5, с. 53-89; 10, с. 19-32]. По выражению К. Фокс, «наши правила скромности служат противовесом нашей врожденной заносчивости, равно как наши правила вежливости защищают нас от нашей же агрессивности» [12, с. 490]. Поскольку при моделировании поведения англичане руководствуются принципами «Не хвались», «Не умничай», «Не будь назойливым», хвалить собственный обед без употребления смягчающего / think было бы неприлично.

В примере (10) автор «помогает» племяннице Скруджа скрыть резкость прямолинейного высказывания о богатстве дяди постановкой в начале обоих предложений прагматических маркеров - предикативного I'm sure и непредикативного At least:

(10) "I'm sure he is very rich, Fred," hinted Scrooge's niece. "At least, you always tell me so." (p. 98)

"Он ведь очень богат, Фред," - заметила племянница. 
- "По крайней мере, ты всегда мне это говорил." (с. 79)

Встраивание в предложение маркера помогает автору показать читателю эмоциональное состояние действующего лица.

В следующем примере (11) императив show that person to me привлечен для выражения просьбы. Ее нейтральный оттенок при присоединении маркера I beseech уои! теряет нейтральность, получает сильную эмоциональную окраску, и, имея предшествующим quite agonized, создает картину крайнего напряжения:

(11) "If there is any person in the town who feels emotion caused by this man's death," said Scrooge, quite agonized, "show that person to me, Spirit, I beseech you!"(p. 110)

"Если есть в этом городе хоть одна душа, которую эта смерть не оставит равнодушной," - вне себя от муки вскричал Скрудж, "покажи мне ее, дух, молю тебя!" (с. 100)

Маркер I am sure в реплике (12) выполняет своеобразную роль - будто бы показывая неуверенность, сомнение говорящего в правильности понимания предыдущей услышанной реплики, он на самом деле предоставляет возможность собеседнику переменить мнение или возразить:

(12) "Christmas a humbug, uncle!" said Scrooge's nephew. "You don't mean that, I am sure?" (p. 58)

"Это Святки - чепуха, дядюшка?" - переспросил племянник. "Верно, я вас не понял!" (с. 11)

В примере (13) маркер / tell уои, используемый, если говорить о типе речевого акта, как перформатив, встраиваясь между повторяющимися восклицаниями, придает высказыванию целый букет значений - неуверенность, страх, обескураженность, растерянность, настойчивость Скруджа в желании убедить самого себя, что того, что происходит (явления привидения и разговора с ним), просто не может быть:

(13) "... Humbug, I tell you: humbug!" (p. 67)

"...Словом, это все вздор! Вздор и вздор!" (с. 26)

Маркер I dare say в ДЕ (14), скорее всего, предназначен автором для того, чтобы показать смущение говорящего, находящегося в не совсем привычной для него ситуации. Довольно циничное высказывание о том, что покойнику одеяло ни к чему, при этом несколько смягчается:

(14) "His blankets?" asked Joe.

"Whose else's do you think?" replied the woman. "He isn't likely to take cold without 'em, I dare say." (p. 109)

"Это его одеяло?" - спросил старьевщик. "А чье же еще?" - отвечала женщина. "Теперь небось и без одеяла не простудится!" (с. 97)

В ДЕ (15) маркер / suppose употребляется с эллиптическим предложением, представляющим компонент саркастического утверждения, что покойному не станет хуже без украденных вещей, помогает подчеркнуть неприязнь говорящего к тому, кого он подразумевает.

(15)"(...) Who's the worse for the loss of a few things like these? Not a dead man, I suppose?" (p. 107)

"Подумаешь, велика беда, если они там недосчитаются двух-трех вещичек вроде этих вот. Покойника от этого не убудет, думается мне." (с. 95)

В следующем примере маркер / fear предназначен для выражения сожаления, подчеркивания искренности просьбы Скруджа о прощении:

(16) "Yes," said Scrooge. "That is my name, and I fear it may not be pleasant to you. Allow me to ask your pardon. [...]"(p. 119)

"Совершенно верно," - отвечал Скрудж. "Это мое имя, но боюсь, что оно звучит для вас не очень-то приятно. Позвольте nопросить у вас прощения." (с. 113)

Для изображения глубокого раскаяния Диккенс, формируя речь своего персонажа, выбирает маркер I assure уои (реплика 17):

(17) "Not a farthing less. A great many back-payments are included in it, I assure you." (p. 119)

"Поверьте, этим я оплачиваю часть своих старинных долгов." (с. 113)

В эмоциональном высказывании Скруджа о том, что времени терять нельзя, представленном в отрывке (18), маркер I know помогает подчеркнуть уверенность говорящего в правильности выбора и решимость довести дело до конца:

(18)"Lead on!" said Scrooge. "Lead on! The night is waning fast, and it is precious time to me, I know. Lead on, Spirit!" (p. 104)

"Веди меня!" - сказал Скрудж. "Веди! Ночь быстро близится к рассвету, и каждая минута для меня драгоченна - я знаю это. Веди же меня, призрак!" (с. 90)

Формируя речь персонажей и придавая ей естественность и необходимые оттенки значений, Ч. Диккенс использует прагматические маркеры, которые употребляют его современники. Можно видеть, что одни и те же маркеры характерны для речи представителей разных социальных слоев и различного рода занятий независимо от возраста - почтенного джентльмена и поденщицы, коммерсанта и клерка, мальчишки и немолодого уже Скруджа.

Клерк Боб Крэтчит, беседуя со своим сыном, употребляет конструкцию с прагматическим маркером / hope. Боб разделяет мнение Питера и доволен ходом его рассуждений, избыточность языковых средств при отражении положительного ответа помогает усилить оттенок симпатии:

(19) "Everybody knows that", said Peter.

"Very well observed, my boy!" cried Bob. "I hope they do." (p. 113) 
"Кто ж этого не знает!" - вскричал Питер. "Правильно, сынок," - сказал Боб. "Все знают." (с. 105)

Пример (20) представляет фрагмент диалога двух джентльменов, богатых и весьма влиятельных. Чтобы вопрос You are not a skater? не был воспринят как нарушение личного пространства, один из собеседников использует маркер / suppose:

(20) "Cold, isn't it?"

"Seasonable for Christmastime. You are not a skater, I suppose?" (p. 105)

"Каков мороз!" "Самый рождественский. Вы не любитель покататься на коньках?" (с. 92)

Почтенный коммерсант в реагирующей реплике ДЕ (21) Last night, употребляет маркер / believe, чтобы избежать излишней краткости и не показаться неучтивым:

(21) "When did he die?" enquired another.

"Last night, I believe." (p. 105)

"Когда же это случилось?" "Да как будто прошедшей ночью." (с. 91)

Мальчишка на улице, отвечая на вопрос Скруджа, вместо краткого уеs или I did, употребляет предложение I should hope I did. Стремление к некатегоричности является доминантной чертой английского коммуникативного поведения, то есть чертой, характерной для всех носителей данного языка и проявляющейся в подавляющем большинстве коммуникативных ситуаций [10, с. 25]. Подросток, таким образом, употребляет привычную ему структуру, говорит, «как все»:

(22) "Do you know the poulterer's in the next street but one, at the corner?" Scrooge enquired.

"I should hope I did," replied the lad. (p. 117)

"Ты знаешь курятную лавку через квартал отсюда, на углу?" - спросил Скрудж. "Ну как не знать!" (с. 111)

Реплика поденщицы (23), выражающей удивление тому, что все посетители пришли в лавку в одно время, включает маркер / believe:

(23)"We knew pretty well that we were helping ourselves before we met here, I believe." (p. 108)

"Ведь не сговариваясь сошлись, видал?" (с. 94)

Маркер придает утверждению оттенок предположения, и в то же время помогает показать, как неуютно чувствует себя женщина, удивляясь и смущаясь одновременно.

Употребление обсуждаемых маркеров, несомненно, связано также с намерением автора указать на речевую привычку персонажа.

Оба предложения ответной реплики в ДЕ (24) представляют собой выражение отрицательного ответа, но не одним словом-предложением No, а с использованием двух структур, каждая из которых содержит в виде главной клауземы интересующие нас маркеры. Как известно, англичане считают краткие ответы да и нет слишком категоричными и по возможности их избегают. При формировании отрицательного ответа автор интересно располагает отрицательную частицу - в первом предложении она находится в клауземе I don't think, во втором - в придаточном предложении I have not.

(24) "Have never walked forth with the younger members of my family; (...)" pursued the Phantom.

"I don't think I have," said Scrooge. "I am afraid I have not." (p. 87)

"Никогда не общался с молодыми членами нашего семейства, из которых я - самый младший? " - продолжал допрашивать призрак. "Как будто нет," - сказал Скрудж. "Боюсь, что нет." (с. 60)

Преследуя определенные цели, автор предоставляет только одному из участников диалога возможность включать в речь обсуждаемые маркеры, как в примере (25):

(25) "You'll want all day tomorrow, I suppose?" said Scrooge.

"If quite convenient, sir."

"It's not convenient," said Scrooge, "and it's not fair. If I was to stop half a crown for it, you'd think yourself ill used, I'll be bound?" (p. 62)

"Вы, небось, завтра вовсе не намерены являться на работу?" - спросил Скрудж. "Если только это вполне удобно, сэр." "Это совсем неудобно," - сказал Скрудж, "и недобросовестно. Но если я удержу с вас за это полкроны, вы ведь будете считать себя обиженным, не так ли?" (с. 18)

Оба маркера размещаются в финале реплик возмущенного работодателя, и представляют собой вводные клауземы в вопросительных предложениях без инверсии. Вероятная цель их употребления - привнесение оттенка неодобрения в предположение того, что клерк хочет взять выходной, и язвительности в замечание, что «справедливый» вычет из жалования будет воспринят с обидой. Отвечая на вопрос Скруджа, его клерк также использует прагматические маркеры, но другого рода - усеченное предложение в условном наклонении и обращение.

Еще одним стилистическим приемом автора является размещение нескольких маркеров в одной реплике, близко друг к другу. Такой прием может применяться для достижения противоположных эффектов, например, для создания картины спокойствия и повседневности или же формирования эмоционального монолога. Так, например, в реплике старьевщика (26), Диккенс располагает два маркера I believe и I am sure очень близко друг к другу:

(26) "There an't such a rusty bit of metal in the place as its own hinges, I believe; and I'm sure there's no such old bones 
here as mine." (p. 107)

"Во всей лавке, верно, не сыщется куска такого старого ржавого железа, как эти петли, и таких старых костей, как моих." (с. 95)

Старик Джо, кажется, произносит это предложение неторопливо и умиротворенно. Его слова заполняют паузу, образовавшуюся в то время, когда он пропускает посетителей внутрь лавки, ждет, пока они пройдут и притворяет за ними дверь. Его добродушное ворчание на скрипящую дверь и сетование на старость передают спокойствие человека, находящегося в привычной ему обстановке и никуда не спешащего. Включение маркеров придает речи обыденность и является указателем на невысокий темп речи, особенно в месте их стыковки, I believe; and I'm sure.

В примере (27) концентрация нескольких маркеров в одном абзаце используется для формирования очень эмоциональной речи:

(27) "There are many things from which I might have derived good, by which I have not profited, I dare say," returned the nephew; "Christmas among the rest. But I am sure I have always thought of Christmastime, when it has come round (...) as a good time (...). And therefore, uncle, though it has never put a scrap of gold or silver in my pocket, I believe that it has done me good and will do me good; and I say, God bless it!" (p. 59)

Племянник Скруджа, говоря о Рождестве, высказывает центральные положения отношения добропорядочного гражданина Викторианской эпохи к этому празднику: Рождество относится к тем хорошим вещам, от которых нет «никакого проку», они не приносят прибыли, однако этот праздник ожидают, как один из самых прекрасных дней в году, он всегда приносил и будет приносить добро, да благословит Бог этот день. Чтобы речь молодого человека не выглядела назиданием, автор превращает ее в живой, эмоциональный монолог, одним из средств придания естественности которому являются маркеры I dare say, I say, I am sure. Использование маркеров также помогает подчеркнуть глубокую убежденность говорящего в правильности высказываемых идей.

Из приведенных выше примеров видно, что обязательными компонентами рассматриваемых маркеров служат местоимение и глагол. При этом местоимение 1-го лица может быть представлено в единственном или множественном числе: I should hope, we should hope. Глаголы, формирующие маркеры - know, say, believe, wonder, suppose, tell, think, confess, hear, hope - образуют сочетания нескольких разновидностей, которые характеризуются большей или меньшей стабильностью:

I hope, I should hope, we should hope

I say, I dare say

I believe, I do believe

I think, I don't think, as I think

\section{Ifear \\ I know \\ I suppose \\ l assure you \\ I beseech you \\ I am sure \\ I am afraid \\ I'll be bound}

Источником разнообразия перечисленных структур служат как объективные, так и субъективные факторы. Среди объективных назовем исторически сложившийся набор глаголов, характерный для периода, в который проживает и создает свое произведение автор. К объективным факторам отнесем также возможность или необходимость привнесения дополнительных элементов к обязательным составляющим. Такая необходимость зависит от валентностных свойств глагола, образующего маркер, а возможность - от «моды» на использование маркера с дополнительным словом. Так, валентностные свойства глагола требуют постановки дополнения уои в сочетаниях I assure уои и I beseech уои. Сочетание I say образует разновидности, принимая модальный глагол dare и формируя структуру I dare say; разнообразие в сочетание I hope вносят модальный глагол should и замена местоимения единственного числа на местоимение множественного числа we, наблюдаем структуры / should hope и we should hope; сочетание I believe «усилено» вспомогательным глаголом do в маркере I do believe; на основе сочетания I think формируются маркеры I don't think и as I think.

Сочетания I fear, I know, I suppose неизменно сохраняют в своем составе только два обязательных составляющих, местоимение и глагол. Маркеры, построенные с глаголом-связкой be, представлены застывшими формами I am sure, I am afraid, I'll be bound.

К субъективным факторам отнесем осуществление автором выбора разновидности маркера и принятие решения о необходимости употребления маркера при создании реплики для данного действующего лица.

В заключение отметим, что рассмотренные модально-предикативные структуры, использованные Ч. Диккенсом при написании диалогов персонажей, входят в состав предложений в репликах, обеспечивающих зачинание, пролонгирование и завершение диалога. Являясь полифункциональными, сочетания I believe, I think, I am sure и др. служат средством формирования неэмоциональной, эмоциональной и очень эмоциональной речи, маркирования и заполнения неуверенной или многозначительной паузы, указания на речевую привычку действующего лица. Сопровождая проявление доминантных черт английского коммуникативного поведения, обсуждаемые маркеры используются представите- 
лями разных социальных слоев для смягчения резкого, категоричного высказывания, потенциально затрагивающего личное пространство собеседника, подчеркива- ния сожаления, сокрытия напряжения, неуверенности, сомнения, страха, изумления, во избежание излишней напористости и пр.

\section{ЛИТЕРАТУРА}

1. Голованова Е.И., Корсакова Ю.И. Функциональная семантика дискурсивных маркеров устной речи: динамический аспект. Известия УрФу. Серия 2. Гуманитарные науки. 2018. Т. 20. № 4 (181). С. 222-241.

2. Джиоева А.А. Англосаксонский менталитет сквозь призму английского языка. М.: МГУ, 2014.152 с.

3. Диккенс Ч. Рождественские повести. Санкт-Петербург: «Азбука-Классика», 2017. С. 7-118.

4. Загороднова 0.А. Прагматическая маркированность как свойство научного текста. Вестник Костромского государственного университета. 2017. Т. 23. № 1. С. 189-192.

5. Ларина Т.В. Англичане и русские. Язык, культура, коммуникация. - М.: Языки славянских культур, 2013. 360 с.

6. Обвинцева 0.В., Перескокова Д.А. Прагматические маркеры англоязычного гастрономического дискурса (на примере кулинарного шоу). Вестник Томского государственного педагогического университета. 2019. № 9 (206). С. 47-53.

7. Обвинцева О.В., Питолин Д.В., Обвинцева Т.О. Прагматические маркеры в англоязычном предвыборном дискурсе (на примере выступлений кандидатов на пост лидера Консервативной партии Великобритании). Научный диалог. 2020. № 1. С. 124-140.

8. Савченко Е.П., Фильчакова Е.М. Функциональные особенности английских контрастивных дискурсивных маркров. Филологические науки. Вопросы теории и практики. 2017. № 6 (72). Ч. 1. С. 130-133.

9. Санжеева Л.Ц. Прагматический аспект использования английских дискурсивных маркеров в разговорной речи. Вестник Бурятского государственного университета. 2017. Вып. 6. С. 53-60.

10. Стернин И.А., Ларина Т.В., Стернина М.В. Очерк английского коммуникативного поведения. Воронеж, 2003. 185 с.

11. Фильчакова Е.М. Функциональные особенности английских позиционных маркеров в условиях коммуникативной ситуации. Вестник Мгоу. Серия «Лингвистика». 2013. № 5. С. 31-35.

12. Фокс К. Наблюдая за англичанами. Скрытые правила поведения. М.: РИПоЛ классик, 2009. 512 с.

13. Dickens Ch.A Christmas Carol. Complete Ghost Stories. Ware: "WORDSWORTH CLASSICS", 2009. P. 56-122.

14. Mueller S. Discourse Markers in Native and Non-native English Discourse. Amsterdam: J. Benjamins, 2005. 290 p.

15. Quirk R., Greenbaum S., Leech G., Svartvik J.A Comprehensive Grammar of the English Language. London: Longman, 2000. 1779 p. 